\title{
DEVOLUTION IN A VIRTUAL ENTERPRISE
}

\author{
Muhammad Kashif Farooq, Shafay Shamail, Mian M Awais \\ LUMS, DHA, Lahore, PAKISTAN \\ \{kashiff, sshamail,awais\}@lums.edu.pk
}

\begin{abstract}
E-Government as a virtual enterprise, having many vertical portals, works in collaborative network to deliver e-services. The decentralization in $e$ governance depends on how much a governance structure decentralizes its political, fiscal and administrative powers. E-governance devolution areas may be planning, business process re-engineering, change management, enterprise architecture, networks, portals, back-offices, e-services, etc. Improper devolution in e-governance may affect cost, implementation, manageability, trust, outsourcing and localization. In this paper, we analyze a centralized web portal with its outcomes and derive a framework for devolution in e-governance. We propose an extension in the Souffle theory of decentralization to calibrate suitable degree of devolution in e-governance. At the end we explain our approach by applying it to a real scenario.
\end{abstract}

\section{INTRODUCTION}

Devolution is a very common mechanism for establishing a decentralized stable governing structure. It may be categorized as political, fiscal and administrative devolution (Yulian, 2004). These can further be defined as transfer of political, fiscal and administrative powers to sub-national level (Janssen, 2005). Devolution with its various types has been implemented in many countries (Work, 2002). Decentralization and devolution are dominant themes in the contemporary discussion of e-governance policy throughout world, and are becoming very popular in many developing countries. Devolution is more institutionalized and is extensive form of decentralization (Janssen, 2005). It means the central government transfers authority like political, decision making, finance and management to local governments through constitutional provisions and legally recognized jurisdiction to provide legal mandate for the local authority to exercise the delegated powers.

Collaboration theory defines two viewpoints, coordination effect and selforganizing. Su and Zhu (2007) discussed these viewpoints in e-government perspective and emphasized that e-government is a collaborative network of government agencies to provide services to citizens and business concerns ( $\mathrm{Su}$ and Zhu, 2007).

Now e-governance or e-government is gaining key position in every level of government structure and involves in 360 degree services like Government to Citizen (G2C), Government to Business (G2B), Government to Government (G2G) and Government to Employees (G2E) (Lee et. al., 2007). A central e-government is also needed to be decentralized as traditional government decentralizes in the form of political, fiscal, or administrative manners (Janssen, 2005). This new type of decentralization or devolution is becoming a challenge for policy makers.

In this paper we are focusing on devolution in e-governance with respect to other devolutions (political, fiscal and administrative) and identify relational constants 
from Soufflé theory (Parker, 1995). The Soufflé theory of decentralization explains the role of political, fiscal and administrative devolutions and their result. We extend it for devolution in e-governance.

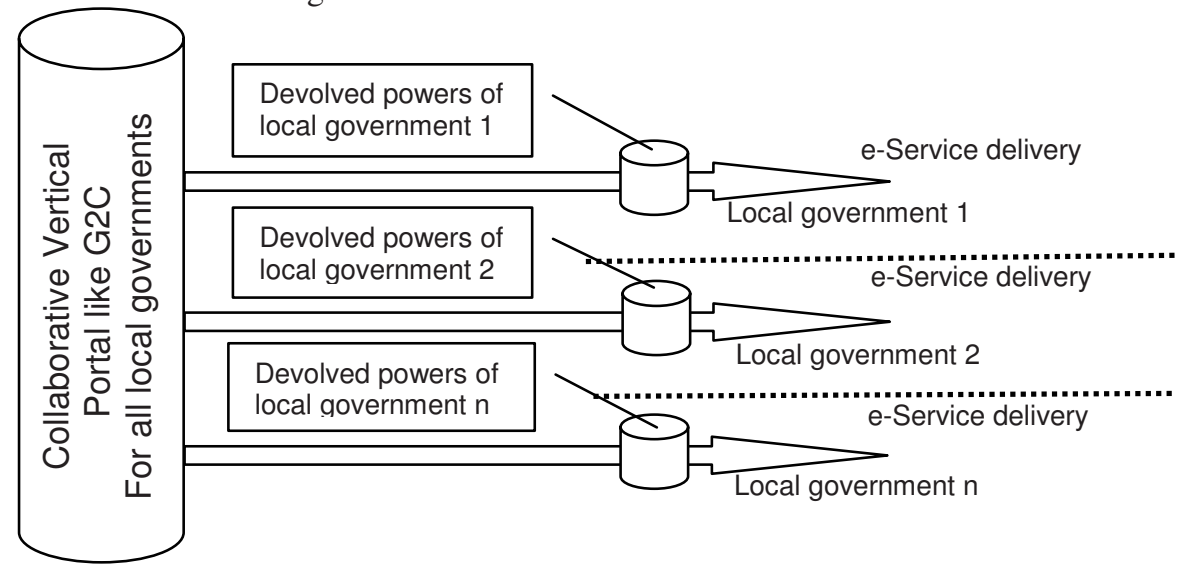

Figure 1 - Vertical Portal Having Devolved Powers

\section{DEVOLUTION IN E-GOVERNANCE FOR COLLABORATIVE APPROACH}

E-government structure is very complex and needs to be analyzed that how many administrative components or how much power should be centralized and how much decentralized. It all depends on recourses, manageability trust and quality of services. Generally there are two approaches of devolution for stable governing structures: devolution among multilevel governments, and devolution among institutions. These types are discussed below.

\section{1. e-Government Devolution among Multilevel Government Structure}

Many governments use strategy of centralized e-government initiatives, portals and services to reduce cost and integration issues. They share technical, financial and HR resources. In federated structure, federal government becomes the owner of the project and lower governments with their agencies become the collaborative partners of that project. So, federal government has to plan a detailed policy about devolution. In multilevel government structure, a centralized portal providing services to all levels of governments may be named as vertical portal. Figure 1 shows the relationship between a central vertical portal and the power devolved as a result of decentralization. In such cases one centralized G2C portal provides services to all local governments. Portal of a particular government agency that has no vertical (multi level government) structure, such as foreign and defense office, the portal may be named as horizontal portal. Centralized virtual office and backend offices are the most optimum structure in which a centralized virtual office provides services to multiple backend offices (Homburg, 2002). In this form of devolution the governing structures should select institutions to be devolved among different levels of governments such as health and education. Where as institutions such as defense and foreign office need not to be decentralized 


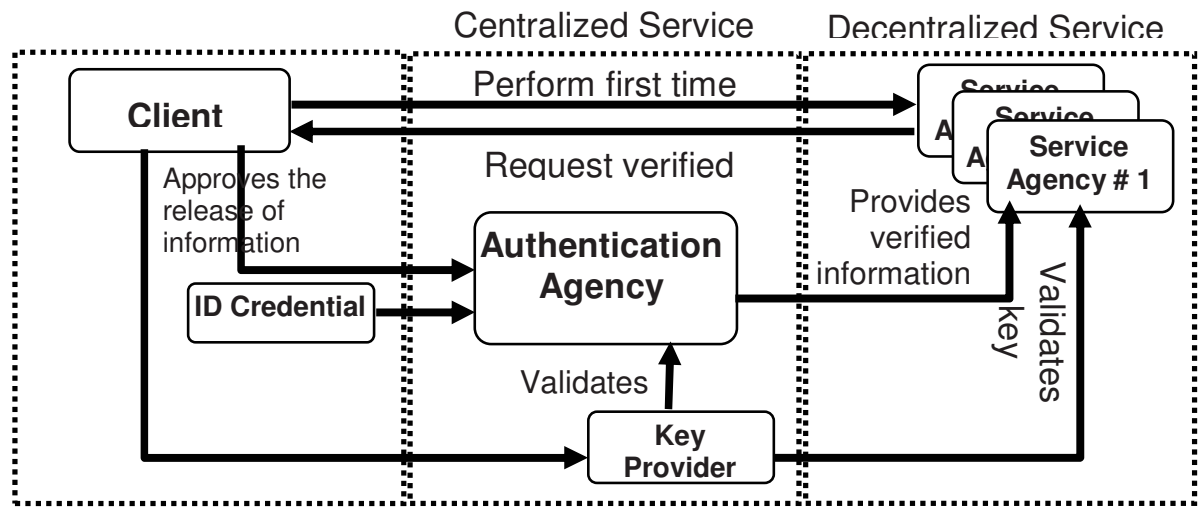

Figure 2 - Collaboration of Centralized and Decentralized Services

\subsection{Institutional Devolution/Collaboration for e-Government}

Many governments use strategy to integrate many services related to different agencies on one portal. It is much more convenient for end user to access one portal that provides all services from birth of a citizen to death. For this purpose many agencies or departments have to be collaborated on one portal. A decentralization or devolution plan among different agencies at same government level or among different decentralized government levels is required for this portal. Figure 2 shows collaborated services among different agencies (Adam et. al.,2005, Kolsaker, 2005, Ho , 2002, Chun et. al., 2002, Homburg, 2004, Lee, 2005, Hu et.al., 2006). For example to provide centralized authentication, an agency can provide verification service to all decentralized agencies, such as to health agencies of all local governments. The trust in inter-organizational relationships is similar across most of such cases. Tolbert et al (2003) conclude that higher trust levels lead to lower costs. Political approaches and institutional analyses also have shown that trust is an important factor in governance mechanism across organizations. But these structural approaches do not account for how trust develops (Tyworth and Sawyer, 2006).

\section{PROPOSED MODEL FOR DEVOLUTION IN E- GOVERNANCE}

Governance is a complex structure and depends upon many variables. Given that it is devolved into political, financial and administrative sections, the overall impact of governance can be measured by individually measuring the impact of each of these. Devolution of e-governance is not an independent term; it is a relative term and we can safely say that "the sum of Devolution Powers (DP) of e-governance is directly proportional to the sum of Devolution Powers related to Political, Financial and Administrative factors". This can be represented in the following form:

$\mathrm{DP}_{\mathrm{eGov}}=$ Devolved Power of e-governance

$\mathrm{DP}_{\mathrm{Pol}}=$ Dev olved Power of Political

$\mathrm{DP}_{\text {Fin }} \quad=$ Devolved Power of Financial 


$$
\begin{aligned}
& \mathrm{DP}_{\mathrm{Adm}}=\text { Devolved Power of Administration } \\
& \Sigma \mathrm{DP}_{\mathrm{eGov}} \alpha\left(\Sigma \mathrm{DP}_{\mathrm{Pol}}+\Sigma \mathrm{DP}_{\mathrm{Fin}}+\Sigma \mathrm{DP}_{\mathrm{Admin}}\right) \\
& \Sigma \mathrm{DP}_{\mathrm{eGov}}=k\left(\Sigma \mathrm{DP}_{\mathrm{Pol}}+\Sigma \mathrm{DP}_{\mathrm{Fin}}+\Sigma \mathrm{DP}_{\mathrm{Admin}}\right) \\
& \Sigma \mathrm{DP}_{\mathrm{eGov}}=k_{1} \Sigma \mathrm{DP}_{\mathrm{Pol}}+\mathrm{k}_{2} \Sigma \mathrm{DP}_{\mathrm{Fin}}+\mathrm{k}_{3} \Sigma \mathrm{DP} \mathrm{P}_{\mathrm{Adm}}
\end{aligned}
$$

The relation given above helps us in defining the degree of e-governance devolution in terms of its political, fiscal, and administrative constituents. The proportionality constant $k$ incorporates other empirical factors that may influence the integrated and cohesive functioning of these three constituents. When divided over individual constituents, the proportionality constant $k$ can be broken up into individual contributions for each political, fiscal, and administrative constituent of governance.

The factor $k l$ depends on political will to initiate and institutionalize the egovernance. It also depends on public demand. The factor $k 2$ depends on transparency and Business Process Re-engineering (BPR) in financial structure. It also depends on how much local government is answerable to its citizens about its financial affairs. The factor $k 3$ depends on need or priority to achieve e-governance for command, control and planning. It also depends on e-readiness of local government. In order to identify these parameters, we study Souflle theory of decentralization [16] and extend it for application in the e-governance devolution.

\section{PROPOSED EXTENSION IN SOUFFLE THEORY FOR E- DEVOLUTION IN GOVERNANCE}

\subsection{Soufle Theory}

Parker (1995) presented a conceptual model - named as "Souffle" Theory of decentralization - that explains the role of political, fiscal, and institutional decentralization as they relate to rural development outcomes. Like a souffle that needs just the right combination of milk, eggs, and heat to rise, a successful program of decentralization must include just the right combination of political, fiscal, and institutional elements to improve rural development outcomes.

\subsection{Extension in Soufle Theory}

In this paper, an extension in Souffle Theory is being suggested to define egovernance devolution. Possible areas of devolution in e-governance and outcomes of that system have been derived. Then further more system results and development impact of this devolution have also been derived. Proposed extension is described in Table 1 extended from (Parker, 1995). Scale of devolution depends upon the size of the country, its resource base, human capacity and governance style. Large countries with a federated structure might begin with a decentralized approach and then bring in standardization and coordination though a central agency. Table 2 shows the magnitude of $k 1, k 2$, and $k 3$ with respect of decentralized choices for devolution in e-governance. The effect of $k$ can be formulated as given in equation (4).

$k=\#$ of powers to be devolved / total decentralized choices 
Table 1 - Soufflé Theory and Proposed Extension

Source: Adapted from Parker, A. N. Decentralization: The Way Forward for Rural Development? Policy Research Working Paper 1475, The World Bank, Washington, D.C. 1995.

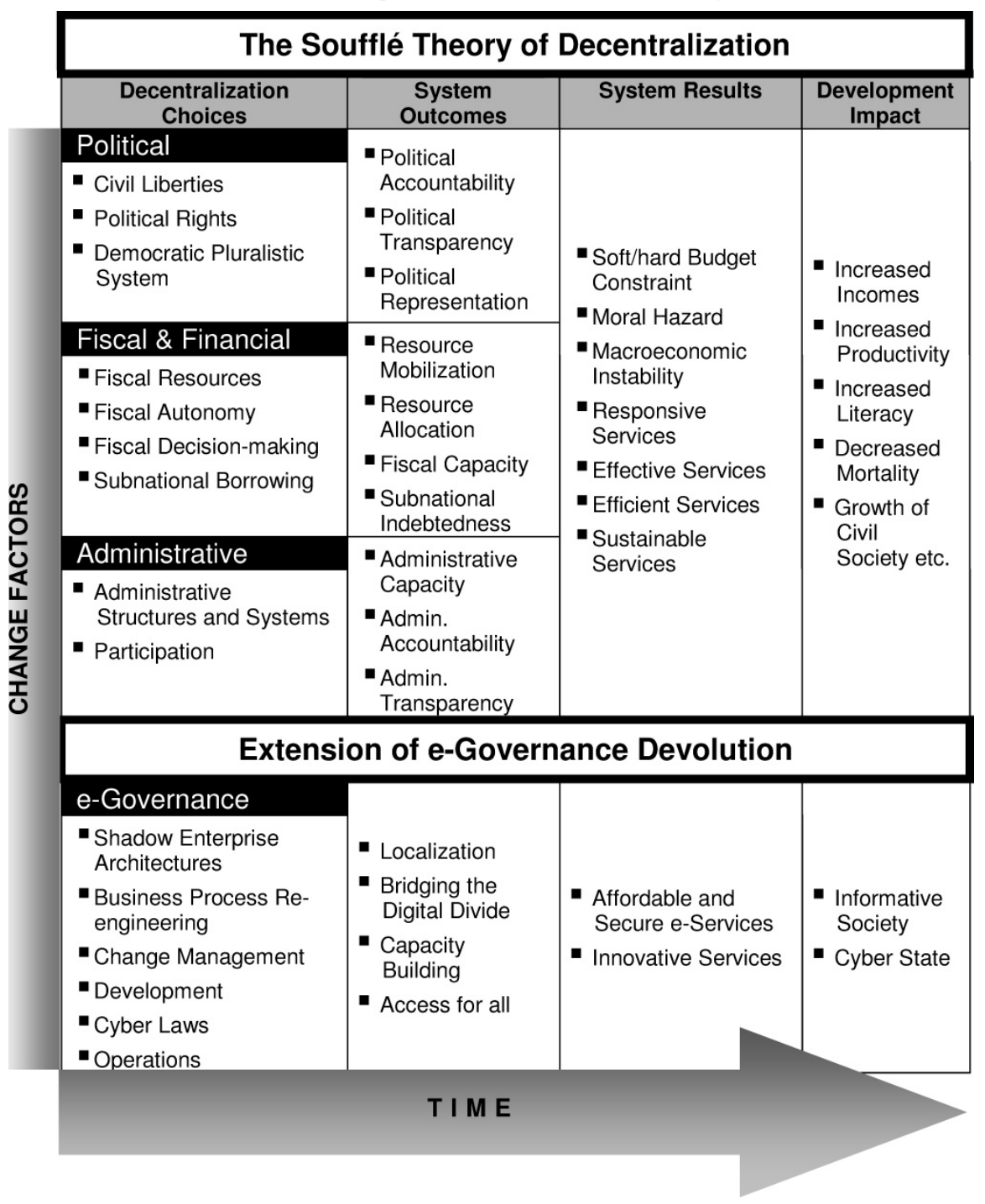

Table 2 - Decentralized choices verses political, financial and administrative devolved powers

\begin{tabular}{|c|c|c|c|c|c|c|}
\hline $\begin{array}{l}\text { Devolution } \\
\text { Powers }\end{array}$ & EA & BPR & CM & $\begin{array}{l}\text { Cyber } \\
\text { Laws }\end{array}$ & Development & Operations \\
\hline Pol & High & High & Medium & Medium & Low & Low \\
\hline Fis & High & High & Medium & Medium & Medium & Low \\
\hline Adm & High & High & High & Medium & Medium & Medium \\
\hline
\end{tabular}




\section{DEGREE OF DEVOLUTION ISSUES: A CASE STUDY}

In this section we study a case of centralized solution for the local governments and departments. The Provincial Government initiated a centralized web portal through an IT agency of provincial government to represent 35 local governments and 40 provincial departments. The IT agency trained personnel from portal partner departments and local governments to update contents.

\subsection{Issues}

11 Local governments and 11 departments launched their independent websites with the passage of time. After detailed interviews with these 22 portal partners, following facts have been concluded.

Portal partners wanted 1) their own graphic design to represent their specific cultural, geographic and professional themes, 2) multi language interface, 3) local news highlights, 4) independent URLs, 5) innovative ideas, 6) more administrative authority than just content updating and 7) more dynamic pages, database access and interactivity. However these portal partners lacked the authority and skill to handle these issues.

\subsection{Solution: Degree of devolution for a virtual enterprise}

Degree of devolution in this centralized initiative can be devised as per corresponding point as mentioned above. Each department and local government should have right and skill to design their own theme or template to represent their specific cultural, geographic values and professional areas. These independent themes or templates can be chosen from independent URL access or template selection utility. We have tested our framework for degree of devolution on three selected local governments A, B, and C. These local governments launched their own websites and came out from the sphere of centralized portal. We estimated capability maturity of these local governments by analyzing their websites and estimating how much devolved powers have been exercised in the area of political, fiscal and administration. These estimates are shown in Table 3. By using Tables 2 and 3, we derived suitable decentralized choices for the selected local governments. These are shown in Table 4. By using equation (5), giving weight to High, Medium, and Low, $k$ values based on equation (4) are calculated and are shown in Table 5. For example, for a virtual enterprise, out of a total number of decentralized choices of 6 , if 4 are devolved then $k$ comes out to be equal to 0.67 .

$k=\#$ of devolved powers that exercised / total decentralized choices

These numbers indicate the relative degree of devolution that these three local governments can exercise if they implement the proposed decentralization choices. 
Table 3 -Political, fiscal and administrative strengths of selected local governments

\begin{tabular}{|l|l|l|l|}
\hline $\begin{array}{l}\text { Local } \\
\text { Govt. }\end{array}$ & Political & Fiscal & Administrative \\
\cline { 2 - 4 } A & High & High & High \\
\hline B & Medium & Medium & High \\
\hline C & Medium & Medium & Medium \\
\hline
\end{tabular}

Table 4 -Suitable decentralized choices (from Tables 2 and 3)

\begin{tabular}{|l|l|}
\hline Local Govt. & Powers to be devolved \\
A & All \\
B & CM, Cyber Laws, Development and Operations \\
\hline C & Cyber Laws, Development and Operations \\
\hline
\end{tabular}

Table 5 - Assignment of $k 1, k 2$ and $k 3$ for selected local governments

\begin{tabular}{|l|l|l|l|}
\hline Local Govt. & Political $k_{1}$ & Fiscal $k_{2}$ & Administrative $k_{3}$ \\
\cline { 2 - 4 } A & 1 & 1 & 1 \\
B & 0.67 & 0.67 & 1 \\
C & 0.67 & 0.67 & 0.67 \\
\hline
\end{tabular}

\section{CONCLUSION}

Devolution is the need of every enterprise governing structure. In this paper, we have proposed and discussed a framework to assess the degree of devolution in egovernance. It is analyzed that degree of devolution in e-governance is proportional to other devolutions (political, fiscal and administrative). Proper degree of devolution is important for effective e-services. We have also proposed the extension in Soufflé theory and verified that it also supports the devolution in egovernance. We have applied our proposed framework of devolution in a virtual enterprise in the background of devolution in e-Government and calculated the relative degree of devolution in terms political, fiscal, and administrative strengths.

\section{REFERENCES}

1. Adam, N. R., Atluri, V., Chun, S. A., Fariselli, P., Hopper, J. C., Bojic, O., Stewart, R. T., Fruscione, J., and Mannochio, N. Technology transfer of inter-agency government services and their transnational feasibility studies. In Proceedings of the 2005 National Conference on Digital Government Research (Atlanta, Georgia, May 15 - 18, 2005). ACM International Conference Proceeding Series, vol. 89. Digital Government Research Center, 225-226.

2. Bhatnagar, S. "Egovernment: Lessons from Implementation in Developing Countries", Indian Institute of Management, Amedabad - 380015 , Published in Regional Development Dialogue, Vol. 24, UNCRD, Autumn 2002 Issue.

3. Chun, S. A., Atluri, V., and Adam, N. R. Dynamic composition of workflows for customized eGovernment service delivery. In Proceedings of the 2002 Annual National Conference on Digital Government Research (Los Angeles, California, May 19 - 22, 2002). ACM International Conference Proceeding Series, vol. 129. Digital Government Research Center, $1-7$.

4. Ferro, E. Cantamessa, M. and Paolucci, E. 2005. Urban vs. Regional Divide: Comparing and Classifying Digital Divide, Lecture Notes in Computer Science, Volume 3416/2005. Springer Berlin / Heidelberg New York, 81-90. 
5. Heeks, R. "The Core-Periphery Approach to Management of Public Information Systems” IDPM, University of Manchester, UK, 1999, Published in: "Government IT"

6. Ho, A.T. "Reinventing Local Governments and the E-Government Initiative" Iowa State University, "Public Administration Review" July/August, Vol. 62, No. 4, 2002.

7. Homburg, V. and Bekkers, V. "The Back-Office of E-Government, (Managing Information Domains as Political Economies)", Proceedings of the 35th Hawaii International Conference on System Sciences - 2002.

8. Homburg, V. E-government and NPM: a perfect marriage? In Proceedings of the 6th International Conference on Electronic Commerce, (Delft, The Netherlands, October 23-27, 2004). ICEC '04, ACM International Conference Proceeding Series, vol. 60. 547-555.

9. $\mathrm{Hu}, \mathrm{P}$. J. Cui, D. and Sherwood, A. C. "Examining Cross-Agency Collaborations in EGovernment Initiatives", Proceedings of the 39th Hawaii International Conference on System Sciences - 2006.

10. Janssen, M. Centralized or decentralized organization? In Proceedings of the 2005 National Conference on Digital Government Research, (Atlanta, Georgia, May 15-18, 2005). ACM International Conference Proceeding Series, vol. 89. Digital Government Research Center, 247-248.

11. Janssen, M., Kuk, G., and Wagenaar, R. W. A survey of e-government business models in the Netherlands. In Proceedings of the 7th international Conference on Electronic Commerce (Xi'an, China, August 15 - 17, 2005). ICEC '05, vol. 113. ACM Press.

12. Kolsaker, A., E-Government: Towards Electronic Democracy, chapter: Third Way eGovernment: The Case for Local Devolution, Lecture Notes in Computer Science, Volume 3416/2005. Springer Berlin / Heidelberg New York, 70-80.

13. Kostopoulos, G. K. e-Government in the Arabian gulf: a vision toward reality. In Proceedings of the 2003 Annual National Conference on Digital Government Research (Boston, MA, May 18 - 21, 2003). ACM International Conference Proceeding Series, vol. 130. Digital Government Research Center, 1-7.

14. Lazer, D. and Binz-Scharf, M. C. Managing novelty and cross-agency cooperation in digital government. In Proceedings of the 2004 Annual National Conference on Digital Government Research (Seattle, WA, May 24 - 26, 2004). ACM International Conference Proceeding Series. Digital Government Research Center, 1-2.

15. Lee, S. M., Tan, X., and Trimi, S. Current practices of leading e-government countries. Communications of the ACM 48, 10 (Oct. 2005), 99-104.

16. Luna-Reyes, L. F. Cresswell, A. M. and Richardson, G. P. "Knowledge and the Development of Interpersonal Trust: a Dynamic Model", Proceedings of the 37th Hawaii International Conference on System Sciences - 2004.

17. Parker, A. N. Decentralization: The Way Forward for Rural Development? Policy Research Working Paper 1475. The World Bank, Washington, D.C. 1995.

18. Su, F., Zhu, H., in IFIP International Federation for Information Processing, Volume 252, Integration and Innovation Orient to E-Society Volume 2, eds. Wang, W., (Boston: Springer), 2007, 390-396.

19. Tolbert, C. and Mossberger, K. The effects of e-government on trust and confidence in government. In Proceedings of the 2003 Annual National Conference on Digital Government Research (Boston, MA, May 18 - 21, 2003). ACM International Conference Proceeding Series, vol. 130. Digital Government Research Center, 1-7.

20. Tyworth, M. and Sawyer, S. 2006. Organic development: a top-down and bottom-up approach to design of public sector information systems. In Proceedings of the 2006 international Conference on Digital Government Research (San Diego, California, May 21 - 24, 2006). dg.o '06, vol. 151. ACM Press.

21. Work, R. Overview of Decentralisation Worldwide: A Stepping Stone to Improve Governance and Human Development, 2nd International Conference on Decentralisation, (Manila, Philippines, July 25-27, 2002).

22. Yulian, E. L. "Decentralization, deconcentration and devolution: what do they mean?" Interlaken Workshop (Interlaken, Switzerland April 27 - 30, 2004). 